\title{
Cooperative Catalysis of Samarium Diiodide and Mercaptan in a Stereoselective One-Pot Transformation of 5-Oxopentanals into $\delta$-Lactones
}

1999

Vol. 1, No. 12

1989-1991

\author{
Jue-Liang Hsu, Chao-Tsen Chen, and Jim-Min Fang* \\ Department of Chemistry, National Taiwan University, Taipei, Taiwan 106, \\ Republic of China
}

jmfang@mail.ch.ntu.edu.tw

Received October 16, 1999

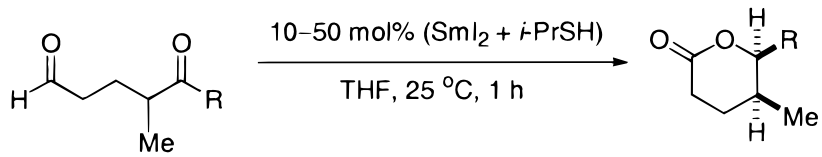<smiles>[R]C(C)C[C@H](CCC=O)C(C)=O</smiles><smiles>[R]C1CC[C@H]2CCC(=O)O[C@H]2C1</smiles>

We demonstrate a general method for conversion of various 5-oxopentanals to substituted $\delta$-lactones and 1-oxa-2-decalones by the synergistic catalysis of samarium diiodide and 2-propanethiol (or disulfide). The deliberate use of mercaptan is advantageous to facilitate the catalytic cycle. This method shows high stereoselectivities, and an enantioselective procedure is feasible by using the chiral mercaptan (1R,2S)-1phenyl-2-( $N$-acetamido)propanethiol as a promoter.

Many natural products, such as insect pheromones and food flavors, incorporate the core structure of $\delta$-lactones, which also attract a number of synthetic approaches. ${ }^{1}$ Uenishi and co-workers ${ }^{2}$ have demonstrated that 5-oxo-4-silyloxyhexanals can undergo the intramolecular Tishchenko oxidoreductions ${ }^{3}$ by reactions with stoichiometric amounts of $(t-\mathrm{BuO}) \mathrm{SmI}_{2}$ or an aged $\mathrm{SmI}_{2}$ solution (presumably containing $\mathrm{Sm}^{3+}$ ion) to

(1) (a) Ohloff, G. Fortschr. Chem. Org. Naturst. 1978, 35, 431. (b) Mulzer, J. In Comprehensive Organic Functional Group Transformations; Katrizky, A. R., Meth-Cohn, O., Rees, C. W., Eds.; Elsevier: Oxford, 1995; Vol. 5, pp 121-179. (c) Ley, S. V.; Cox, L. R.; Meek, G. Chem. Rev. 1996, 96, 423. (d) Collins, I. J. Chem. Soc., Perkin Trans. 1 1998, 1869.

(2) Uenishi, J.; Masuda, S.; Wakabayashi, S. Tetrahedron Lett. 1991, $32,5097$.

(3) Examples of samarium ion catalyzed Tishchenko reactions: (a) Collin, J.; Namy, J. L.; Kagan, H. B. Nouv. J. Chem. 1986, 10, 229. (b) Evans, D. A.; Hoveyda, A. H. J. Am. Chem. Soc. 1990, 112, 6447. (c) Curran, D. P.; Wolin, R. L. Synlett 1991, 317. (d) Molander, G. A.; McKie, J. A. J. Am. Chem. Soc. 1993, 115, 5821. (e) Chuang, T.-H.; Fang, J.-M.; Jiaang, W.T.; Tsai, Y.-M. J. Org. Chem. 1996, 61, 1794. (f) Lu, L.; Chang, H.-Y.; Fang, J.-M. J. Org. Chem. 1999, 64, 843. give the corresponding $\delta$-lactones. The authors also indicated that the silyloxy substituent is essential for such transformations. Otherwise, unsubstituted substrates such as 5-oxohexanal afford only low yields $(\sim 10 \%)$ of $\delta$-methyl- $\delta$-lactone on treatment with $(t-\mathrm{BuO}) \mathrm{SmI}_{2}$ or simply the pinacolic coupling product on treatment with a freshly prepared $\mathrm{SmI}_{2}$ solution. We found previously ${ }^{3 e}$ that transformation of 5-trimethylsilyl-5-oxopentanal into $\delta$-trimethylsilyl- $\delta$-lactone can be carried out by using stoichiometric amounts of $\mathrm{SmI}_{2}$ and methanol. This reaction is presumably initiated by addition of $\mathrm{MeOH}$ to the aldehyde group to form a hemiacetal with the assistance of samarium ion. After an intramolecular hydride transfer to the ketone group (Tishchenko reaction), ${ }^{3}$ a cyclization of the $\delta$-hydroxyester intermediate would give the observed $\delta$-lactone product. On the basis of this speculation, one can conceive a catalytic method for transformation of 5-oxopentanals into their 
corresponding $\delta$-lactones. Indeed, we report herein a general and efficient one-pot procedure by using $\mathrm{SmI}_{2}$ and 2-propanethiol $(i-\mathrm{PrSH})$ as the combined catalysts.

As shown in Scheme 1, a series of 5-alkyl- and 5-phenyl5-oxopentanals $1 \mathbf{a}-\mathbf{g}$ were successfully converted to the

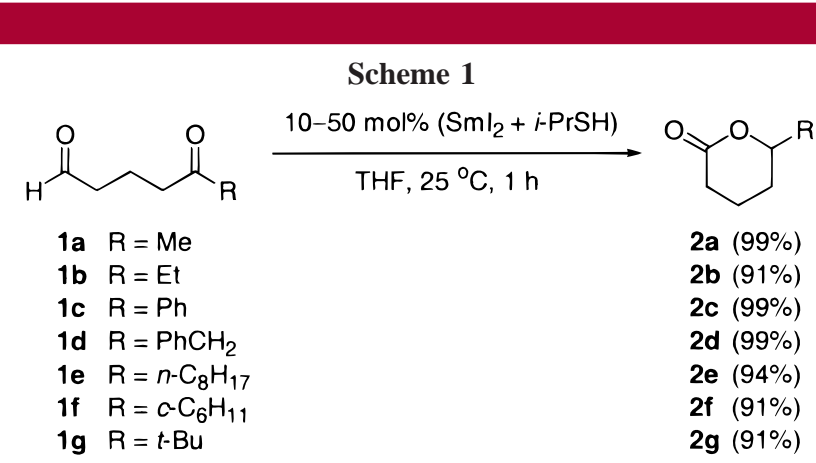

modified procedure by premixing an aliquot of $\mathrm{SmI}_{2} / i-\mathrm{PrSH}$ $(1-5 \mathrm{~mol} \%$ in $1 \mathrm{~mL}$ of THF) with the substrate $(\mathbf{1 a}-\mathbf{g})$ in an oven-dried syringe. The resulting yellow solution, an indication of the presence of trivalent samarium ion, was then added dropwise to the original $\mathrm{SmI}_{2} / i$-PrSH solution. Accordingly, the desired lactones $\mathbf{2} \mathbf{a}-\mathbf{g}$ were also obtained in excellent yields $(>90 \%)$.

By replacing $\mathrm{SmI}_{2} / i$-PrSH with $\mathrm{SmI}_{2} /(\mathrm{MeS})_{2},{ }^{5}$ the reaction of $1 \mathbf{e}\left(\mathrm{R}=n-\mathrm{C}_{8} \mathrm{H}_{17}\right)$ also proceeded smoothly to give $2 \mathbf{e}$ in a comparable yield. The in situ generated $(\mathrm{MeS}) \mathrm{SmI}_{2}$ was considered as the reactive catalyst. ${ }^{5}$ By using $\mathrm{SmI}_{3} / i$-PrSH instead of $\mathrm{SmI}_{2} / i-\mathrm{PrSH}$, the reaction gave a 1:1 mixture of isopropyl thioesters of tridec-4-enoic acid and tridec-5-enoic acid according to NMR analysis. It seemed that the intermediary $\delta$-oxyacid thioester (analogue of $\mathbf{B}$ in Figure 1, R

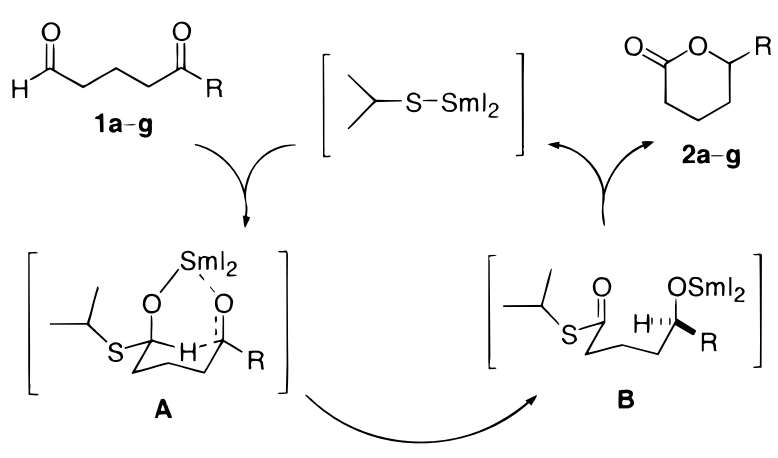

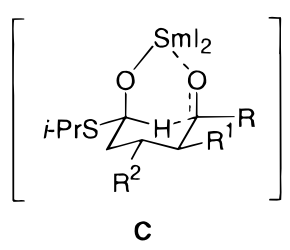

favorable transition states for cis-8a,b and trans-9 with substituents on the equatorial positions

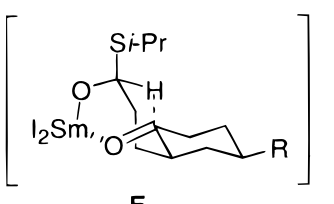

E

favorable transition states for trans-10,b with hydride transfer to the axial positions cyclohexanones

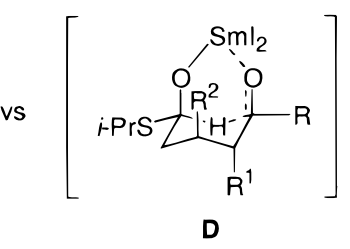

unfavorable transition states due to the steric effects of substituents on the axial positions 6a $\mathrm{R}=\mathrm{H}$

10a $(70 \% ; 9,10-$ trans $/$ cis $=94: 6)$

6b $R=t-B u ; 2,4-c i s$
$10 \mathrm{~b}(91 \% ; 9,10-$ trans $/$ cis $=81: 19)$ corresponding $\delta$-substituted- $\delta$-lactones $\mathbf{2} \mathbf{a}-\mathbf{g}^{4}$ by the catalysis of $\mathrm{SmI}_{2} / i-\mathrm{PrSH}(10-50 \mathrm{~mol} \%)$. No aldol or pinacol products were observed under these reaction conditions.

The following procedure is typical. Under an atmosphere of argon, $i$-PrSH $(0.01 \mathrm{~mL}, 0.1 \mathrm{mmol})$ was added to a deep blue $\mathrm{SmI}_{2}(0.2 \mathrm{mmol})$ solution freshly prepared from samarium and 1,2-diiodoethane in THF (15 mL). The mixture was stirred for $10 \mathrm{~min}$ at room temperature, and a THF solution (5 mL) of 5-oxo-5-phenylpentanal (1c, $176 \mathrm{mg}, 1.0$ mmol) was added dropwise. The mixture was stirred for $1 \mathrm{~h}$ and then filtered through a short silica gel column by elution with EtOAc/hexane (1:1). The filtrate was concentrated by rotary evaporation to give the practically pure lactone 2c (174 $\mathrm{mg}, 99 \%)$. We also conducted reactions using a slightly
Figure 1. Proposed catalytic cycle and the favorable transition states for the formation of $\delta$-lactones.

$\left.=n-\mathrm{C}_{8} \mathrm{H}_{17}\right)$ was diverted to dehydration under such reaction conditions. ${ }^{6}$ The reaction of $\mathbf{1 c}(\mathrm{R}=\mathrm{Ph})$ with stoichiometric amounts of $\mathrm{SmI}_{3}$ and $i$-PrSH also gave an $83 \%$ yield of 5-phenylpent-4-enoic acid isopropyl thioester. ${ }^{6}$ When 1c was treated with stoichiometric amounts of $\mathrm{SmI}_{2}$ and $i$-PrOH, a 
1:1 mixture of isopropyl 5-hydroxy-5-phenylpentanoate and 1-phenyl-1,2-cyclopentanediol were obtained as a consequence of the intramolecular Tishchenko oxidoreduction and pinacolic coupling.

On the basis of the above experimental results, one can propose a possible reaction mechanism for the formation of $\delta$-lactones (Figure 1). A Lewis acid such as the presumed $(i-\mathrm{PrS}) \mathrm{SmI}_{2}$ or the related samarium species ${ }^{3 \mathrm{a}, 5,7}$ can promote the addition of $i$-PrSH to the aldehyde group of a 5-oxopentanal substrate. The samarium-bound hemithiolacetal intermediate (A) can undergo an intramolecular hydride shift to give the $\delta$-oxyacid thioester $(\mathbf{B}) .^{3 \mathrm{~d}}$ The reaction would proceed further with an irreversible lactonization and release the catalyst ( $i$-PrS) $\mathrm{SmI}_{2}$ (or the related samarium species) for the next cycle. The deliberate use of mercaptan is advantageous, because mercaptan is a better nucleophile than alcohol on addition to the aldehyde group. The resulting thioester is also more reactive than ester in the subsequent lactonization; thus the catalytic cycle is facilitated.

The $\mathrm{SmI}_{2} / i$-PrSH-catalyzed reaction of bulky substrate $\mathbf{3}$ still proceeded smoothly to give $\delta$-lactone 7 (Scheme 1 ). ${ }^{4 h}$ A variety of substituted 5-oxopentanals 4-6 also underwent the $\mathrm{SmI}_{2} / i$-PrSH catalyzed reactions in highly stereoselective manners. Lactones 8a, $\mathbf{b},{ }^{4 i, j}$ derived from 4-methyl-5-oxopentanals $\mathbf{4 a}, \mathbf{b}$, had the cis configuration as indicated by a small coupling constant $(\sim 3 \mathrm{~Hz})$ between $\mathrm{H}-5$ and $\mathrm{H}-6$. Treatment of 3-methyl-5-oxo-5-phenylpentanal (5) in an $\mathrm{SmI}_{2} / i$-PrSH solution at $25^{\circ} \mathrm{C}$ gave lactone 9 as a mixture of trans and cis isomers (77:23). ${ }^{4 \mathrm{k}}$ The trans/cis isomeric ratio was increased substantially to $94: 6$ by performing the reaction at a lower temperature $\left(0{ }^{\circ} \mathrm{C}\right)$. The trans lactone showed an NOE correlation between Me-4 and H-6, whereas the cis isomer was devoid of this effect. The $\mathrm{SmI}_{2} / i-\mathrm{PrSH}-$

(4) All the $\delta$-lactones $\mathbf{2 a}-\mathbf{g}, \mathbf{7}, \mathbf{8 a}, \mathbf{b}, \mathbf{9}$, and $\mathbf{1 0 a}, \mathbf{b}$ are fully characterized by spectral methods (IR, MS, HRMS, ${ }^{1} \mathrm{H}$ and ${ }^{13} \mathrm{C}$ NMR). (a) White, J. D. Somers, T. C.; Reddy, G. N. J. Org. Chem. 1992, 57, 4991, for compound 2a. (b) Utaka, M.; Watabu, H.; Takeda, A. J. Org. Chem. 1987, 52, 4363, for compounds $\mathbf{2 b}$ and 2e. (c) Downham, R.; Edwards, P. J.; Entwistle, D. A.; Hughes, A. B.; Kim, K. S.; Ley, S. V. Tetrahedron: Asymmetry 1995, 6, 2403, for compound 2c. (d) Barluenga, J.; Lopez, P. J.; Campos, J. A. Tetrahedron 1983, 39, 2863, for compound 2d. (e) Haase, B.; Schneider, M. P. Tetrahedron: Asymmetry 1993, 4, 1017, for compound $(R)-2 \mathrm{e}$. (f) Otsubo, K.; Kawamura, K.; Inanaga, J.; Yamaguchi, M. Chem. Lett. 1987, 1487, for compound 2f. (g) Garner, P.; Anderson, J. T. Tetrahedron Lett. 1997, 38, 6647, for compound 2g. (h) Souma, Y.; Iyoda, J.; Sano, H. Bull. Chem. Soc. Jpn. 1976, 49, 3291, for compound 7. (i) Kobayashi, Y.; Kitano, Y.; Takeda, Y.; Sato, F. Tetrahedron 1986, 42, 2937, for compound 8a. (j) Oshima, M.; Yamazaki, H.; Shimizu, I.; Nisar, M.; Tsuji, J. J. Am. Chem. Soc. 1989, 111, 6280, for compound 8b. (k) Barbero, A.; Blakemore, D. C.; Fleming, I.; Wesley, R. N. J. Chem. Soc., Perkin Trans. 1 1997, 1329 , for compound 9. (1) Griffiths, D. V.; Wilcox, G. J. Chem. Soc., Perkin Trans. 2 1988, 431, for compound 10a. (m) Edward, J. T.; Cooke, E.; Paradellis, T. C. Can. J. Chem. 1982, 60, 2546, for compound 10b. The data relevant to the stereochemical assignments are shown: $2 \mathbf{e}$, the $(R)$ enantiomer, $[\alpha]_{\mathrm{D}}=+38.4\left(\mathrm{CHCl}_{3}\right)$, is more retained than the $(S)$-enantiomer on a Chiralcel OB column by elution with $i-\mathrm{PrOH} / \mathrm{hexane}(2: 98) ; \mathbf{2 g}, \delta_{\mathrm{H}}$ $3.85(1 \mathrm{H}, \mathrm{dd}, J=11.7 \mathrm{~Hz}, J=2.8 \mathrm{~Hz}) ; 8 \mathbf{a}(c i s), \delta_{\mathrm{H}} 4.14(\mathrm{ddd}, J=11.5$, catalyzed reactions of 2-(3-oxopropyl)cyclohexanones $\mathbf{6 a}, \mathbf{b}$ at $25{ }^{\circ} \mathrm{C}$ afforded 1-oxa-2-decalones $\mathbf{1 0 a}, \mathbf{b}$ in a preponderance of the 9,10-trans isomers. ${ }^{41, \mathrm{~m}, 8}$ The trans decalones had $\mathrm{H}-9$ and $\mathrm{H}-10$ at axial positions as characterized by the ddd splitting pattern $(J=10,10,4 \mathrm{~Hz})$ of $\mathrm{H}-9$ in the ${ }^{1} \mathrm{H}$ NMR spectra. ${ }^{4}$

The stereochemical outcomes can be interpreted by comparisons of the transition states $\mathbf{C}$ versus $\mathbf{D}$ and $\mathbf{E}$ versus $\mathbf{F}$ (Figure 1). The transition state $\mathbf{C}$, giving cis-8a,b and trans $\mathbf{- 9}$, is energetically favored due to the equatorial dispositions of substituents $\left(\mathrm{R}^{1}\right.$ or $\left.\mathrm{R}^{2}\right)$, whereas the alternative transition state $\mathbf{D}$ exerts steric repulsions due to the axially oriented substituents. The transition state $\mathbf{E}$, giving trans$\mathbf{1 0 a}, \mathbf{b}$ by having hydride attack the cyclohexanone moiety from the axial direction, is superior to an equatorial attack in the transition state $\mathbf{F}$. Under such circumstances, a product development control also favors the formation of the more stable equatorial alcohol (as shown in $\mathbf{E}$ ). The stereoselectivities are in agreement with the previous finding ${ }^{3 \mathrm{c}, \mathrm{f}}$ of the related intermolecular Tishchenko reactions.

Our current study demonstrates an effective stereocontrol in conversion of 5 -oxopentanals to $\delta$-lactones by the synergistic catalysis of 2-propanethiol and samarium ion. This study also sheds light on the design of enantioselective catalysis by using chiral mercaptans. Our preliminary result using $\mathrm{SmI}_{2}$ and $(1 R, 2 S)$-1-phenyl-2-( $N$-acetamido)propanethiol as the combined catalysts $(50 \mathrm{~mol} \%)$ indicated that 5-octyl-5-oxopentanal (1e) was converted to 6-octyl-3,4,5,6tetrahydropyran-2-one (2e) with predominance of the $(R)$ $(+)$-enantiomer (52\% ee according to the HPLC analysis on a Chiralcel OB column).

Acknowledgment. We thank the National Science Council for financial support.

OL9911526

$5.5,2.8 \mathrm{~Hz}, \mathrm{H}-6) ; \mathbf{8 b}(c i s), 5.48(\mathrm{~d}, J=3.0 \mathrm{~Hz}, \mathrm{H}-6)$; trans-9, $\delta_{\mathrm{H}} 1.09(\mathrm{~d}$, $J=6.2 \mathrm{~Hz}, \mathrm{Me}-4), 5.50$ (dd, $J=7.3,4.6 \mathrm{~Hz}, \mathrm{H}-6) ;$ cis-9, $\delta_{\mathrm{H}} 1.07$ (d, $J=$ $6.4 \mathrm{~Hz}, \mathrm{Me}-4$ ), 5.29 (dd, $J=12.0,3.1 \mathrm{~Hz}, \mathrm{H}-6$ ); trans-10a, $\delta_{\mathrm{H}} 3.28$ (ddd, $J=10.2,10.2,4.2 \mathrm{~Hz}, \mathrm{H}-9)$; cis-10b, $\delta_{\mathrm{H}} 4.44(\mathrm{br} \mathrm{dd}, J=6.7,3.3 \mathrm{~Hz}$, $\mathrm{H}-9$ ); trans-10b, $\delta_{\mathrm{H}} 3.80$ (ddd, $\left.J=10.5,10.4,4.5 \mathrm{~Hz}, \mathrm{H}-9\right) ;$ cis-10b, $\delta_{\mathrm{H}}$ 4.42 (br d, $J=2.6 \mathrm{~Hz}, \mathrm{H}-9$ ).

(5) The $\mathrm{S}-\mathrm{S}$ bond of PhSSPh is reductively cleaved by $\mathrm{SmI}_{2}$, see: (a) Jia, X.; Zhang, Y.; Zhou, X. Synth. Commun. 1994, 24, 387. (b) Taniguchi, Y.; Maruo, M.; Takaki, K.; Fujiwara, Y. Tetrahedron Lett. 1994, 35, 7789.

(6) The reason for the preference of dehydration was unclear, presumably due to $\mathrm{SmI}_{3}$ exhibiting a property of stronger Lewis acid.

(7) It has been reported (ref 3a) that $\mathrm{SmI}_{2}$ reacts with alcohol $\mathrm{ROH}$ to give (RO) $\mathrm{SmI}_{2}$ in the presence of a metallic salt as the electron carrier.

(8) Chandrasekhar, S.; Venkatesan, V. J. Chem. Res, Miniprint 1995 1137. The authors reported that 2-(3-oxopropyl)cyclohexanone (6a) underwent an intramolecular Cannizzaro reaction in boiling $\mathrm{NaOH}$ solution to give 3-(2-hydroxycyclohexyl)propionic acid, which was subjected to lactonization on treatment with concentrated $\mathrm{HCl}$ to give exclusively the trans isomer of $\mathbf{1 0 a}(59 \%)$, based on an analysis of the ${ }^{1} \mathrm{H}$ NMR spectrum $(90 \mathrm{MHz})$. In our hand, the two-step reaction afforded a trans/cis mixture of 10a in a ratio of $91: 9$ based on an analysis of the ${ }^{1} \mathrm{H}$ NMR spectrum $(300 \mathrm{MHz})$ 